\title{
THE PLACE OF SURGERY IN THE TREATMENT OF CARCINOMA OF THE CERVIX
}

\author{
By John Howkins, M.S., M.D., F.R.C.S., F.R.C.O.G. \\ Gynaecological Surgeon to St. Bartholomew's Hospital, Hampstead General and the Royal Masonic Hospitals
}

To understand the evolution of the treatment of cancer of the cervix, it is profitable to glance back over the last fifty years. At the turn of the century, the great master of pelvic surgery, Victor Bonney, watched Wertheim perform his operation and decided to embark on a series that ultimately exceeded five hundred. His initial mortality of I4 per cent. must have proved an incontrovertible deterrent to a less courageous man but it must be remembered that he knew no anaesthetic perfection such as we enjoy, that blood transfusion in those days was almost a major operation, that water and electrolyte balance was little understood and that there was no chemotherapy, let alone any antibiotic. The criticism of its high initial mortality gradually undermined the Wertheim operation and the spectacular advances in radiotherapy with a negligible operative danger convinced almost all but Bonney that surgery played no part in the treatment of this disease. The universal acclamation of radiotherapy soon thinned the ranks of those surgeons who were willing and capable of performing the Wertheim operation and only those fortunate enough to have worked with Bonney and his pupils continued the lonely struggle. To him and them we owe the principles which are now accepted in the surgical treatment of carcinoma of the cervix.

A brief consideration of some of these principles is important for the proper understanding of the place for surgery in this disease :

I. Kottmeier of Stockholm ${ }^{1}$ has recently reported a 90 per cent. cure rate for stage I carcinoma of the cervix, the best figure so far obtained by pure radiotherapy. The immediate question that arises from these figures is why the cure rate is not 100 per cent. Dobbie of Birmingham ${ }^{2}$ has supplied the answer by showing that the incidence of gland involvement in a small series in stage $I$ is 15 per cent., and stage II 47 per cent. It is an axiom stressed by Meigs that radiation cannot sterilize an involved lymphatic field and, if this is true, it explains the loss of ten out of every hundred $\frac{\text { con }}{\text {. }}$. patients treated by radiation. In stage II cancer, N the radiation cure rate falls to 65 per cent., the percentage of involved glands in this stage being $\omega$ the comparable figure of 35 per cent. The logical N conclusion is that if we knew which patients ino stage I and II had involved glands, they should have at least a pelvic lymphadenectomy or, as $z$ advocated by Schlinck ${ }^{3}$ and Currie ${ }^{4}$, preliminary응 radiation followed by a Wertheim operation. $\frac{\Phi}{3}$ Although surgery will only cure a percentage 앙 patients with involved glands, it will cure more $\frac{\mathbb{D}}{-}$ than pure radiotherapy.

2. In certain cancers of the cervix adequateby treated by radiotherapy, a number fail to responf to it. This can be proved by serial surface biopsy and a study of the tumour cells and bed after radiation (Glucksmann and Way ${ }^{5}$ ). Failure to respond to radiation provides an incontrovertible $\frac{Q}{\square}$ indication for surgical extirpation.

3. For certain technical reasons, for example $\frac{}{3}$ stenosis of the vaginal vault, it may be impossible to apply an adequate source of radium to the growth and, while these growths can be treated byo supervoltage $\mathrm{X}$-radiation, there is insufficient 3 . published material to provide comparable fiveyear cure rates against the standard Stockholm technique.

4. Carcinoma of the cervix complicated by pelvic inflammatory disease or fibroids has usually을 provided an indication for surgical treatment $\frac{D}{O}$ rather than radiation. If radiation is employed in the presence of pelvic inflammatory disease, Kott- N meier has advised that a laparotomy and bilateral ${ }_{N}$ salpingo-oophorectomy should first be performed and the patient then treated by irradiation. $A \omega$ logical development of such an operation would be? to extend the operation to include pelvic lymphadenectomy. If lymphadenectomy is thoroughly performed, it is a small additional step to complete ${ }^{-}$ the classical Wertheim operation. 


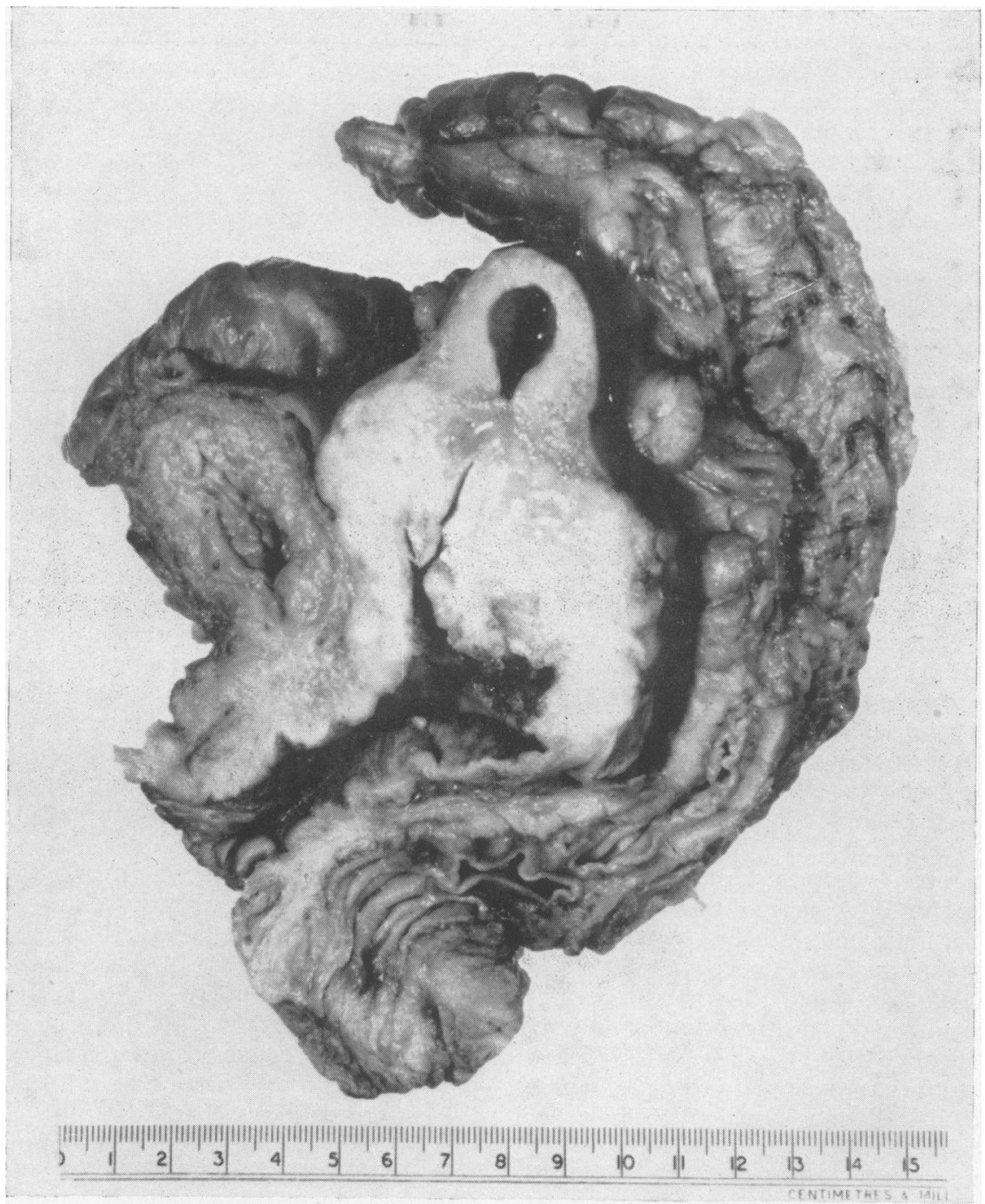

Total exenteration specimen showing infiltration of bladder on left and infiltration and ulceration of rectum on right. The patient survived for fourteen months.

5. In the past adenocarcinoma of the endocervix has been considered unfavourable for radiation by most authorities but Kottmeier and his Stockholm colleagues deny this. He gives a five-year cure rate for adenocarcinoma treated by radiation of $44-45$ per cent. against 43 per cent. treated by surgery. In spite of this, until the superiority of radium or surgery is established beyond doubt, most surgeons would prefer to use surgery for adenocarcinoma of the cervix.

6. In the later stages of cervical cancer when, for instance, the bladder is involved but there is a growth-free space between the parametrial exten- sion and the pelvic wall, the use of radium involves the risk of a vesico-vaginal fistula, and the same argument applies to the rarer involvement of the rectum. In such patients, and especially where the bladder only is involved, some form of exenteration operation should be considered. The anterior exenteration which involves removal of the bladder and implantation of the ureters into some part of the bowel is a reasonable procedure, though the long term cure rate cannot be great even if the growth is confined entirely to the pelvis and is eradicated so that no recurrence endangers the patient. Progressive renal degeneration from anastomotic 
back pressure and retrograde infection will ultimately cost the patient her life. A death from hydronephrosis is certainly more pleasant than one from advanced pelvic cancer with all the misery of urinary and faecal fistula and the malignant cachexia of an infected and advancing growth.

Total exenteration which involves the removal of the rectum in addition to the bladder, uterus and vagina, is an operation which most thinking surgeons still find difficult to justify. Although Brunschwig in New York has claimed a number of five-year survivals after this operation, there cannot be many patients in whom the operation is morally or humanely indicated. It is only fair to explain to the patient, before embarking on such a mutilating procedure, the full implications of her primary disease and the complications and penalties of the operation if successful. It takes a couragenus and intelligent patient to master the water-proofing and management of a Rutzen bag. Therefore, only those who have the moral stamina to tolerate a wet colostomy should be subjected to the operation. It need not be stressed that physical fitness above the average is needed to face the strain of the operation itself and this procedure is unjustifiable in a poor surgical risk. There will, however, be a few patients who are willing and ready to undergo the operation and for them it is a last slender hope of cure.

Before a surgeon starts to treat cancer of the cervix in all its stages by surgery, there are certain essentials which must be fulfilled :

$a$. These operations should never be performed in small hospitals (Howkins ${ }^{6}$ ); so much depends for their success on the team-work that is only available in a big unit that it is safest for the patient for all cases to be segregated in centres where every anaesthetic, radiation, biochemical and other facility is available.

$b$. A long apprenticeship is necessary in which to learn the intricate anatomy of those regions of the pelvis not ordinarily explored by the usual gynaecological operations. For instance, the identification and ligation of the superior and inferior gluteal and pudendal branches of the hypogastric venous system is an essential step in a properly performed radical hysterectomy for carcinoma of the cervix. Failure to ligate these vessels safely and adequately can endanger the patient's life and will prove an insuperable obstacle to a proper dissection. Furthermore, this type of surgery demands quite a considerable knowledge of urological techniques and any surgeon undertaking it must be prepared to implant ureters and make an artificial bladder himself.

$c$. The author cannot pay too great a tribute to Dr. Frankis Evans and Dr. C. J. Massey Dawkins, the anaesthetists who have simplified the technical difficulties of an extended pelvic dissection by superb relaxation and a minimum of unnecessary $\frac{\pi}{\mathbb{2}}$ bleeding. The author's strong preference is for 0

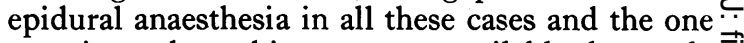
occasion when this was not available has only $\overrightarrow{\overrightarrow{\vec{D}}}$ convinced him of the superiority of the epidural block.

$d$. Pre-operative and post-operative treatment $: \frac{\overline{\bar{D}}}{\bar{c}}$ It is inexcusable to submit any patient to an $\bar{\Phi}$ operation for carcinoma of the cervix who has not first been stabilized at the optimum level. Similarly, the post-operative control of fluid and $\vec{O}$ electrolyte balance must be understood by those $\vec{\longrightarrow}$ clinicians in charge of the case and full laboratory $\omega_{\sigma}$ facilities available for the quick estimation of $\frac{B}{8}$ sodium and potassium.

When the surgeon has marshalled all the neces- $\frac{3}{\dot{\omega}}$. sary facilities, he must make sure that his surgical $N$ treatment carries no greater risk to his patient than $\omega_{\omega}^{\omega}$ the alternative of radiation. In the best hands, $\omega$ such as those of Meigs and Currie ${ }^{7}$, the operative $N$ mortality is in the region of $I$ to 2 per cent. The 0 definition of operative mortality is death from any cause within twenty-eight days of operation and $\vec{z}$ this should be the standard accepted by all surgeons when reporting their results. Any surgeon whose $\frac{\Phi}{3}$ death rate is higher than this should examine he technical approach under the headings considered above.

His next consideration must be the extent of his operation. This primarily demands a thoroug of dissection of those glands which may be involved. These, briefly, are the glands below the bifurcation of the aorta and below the level of the brim of the true pelvis. Ideally, all these glands should be $\frac{Q}{\mathbb{Q}}$ meticulously removed and it is only by this dissec- $\stackrel{\varrho}{\Rightarrow}$ tion that surgery will be able to provide a better $\overrightarrow{\overrightarrow{0}}$ five-year cure rate than radiation. The next most $\frac{3}{5}$ important consideration is the removal as widely as possible of all the potentially involved parametrium and paracolpos and it is here that the author's $\frac{\partial}{3}$ method of synchronous combined abdominovaginal hysterectomy is submitted as being superior to the classical Wertheim's operation ${ }^{6}$. In this method two teams, one working from the vaginal route and one from the abdomen, employ a 0 technique similar to that of Lloyd-Davies in his operation of synchronous combined excision of the $\frac{7}{0}$ rectum and colon. All the parametrium and paracolpos is removed as far laterally as the pelvic o wall and as far downwards as the levator ani $N$ muscles which can then be removed if necessary. N At the end of the operation, the pelvis is empty $\omega$ except for the following structures: The common and external iliac artery and vein, the ureters and $\varrho$ bladder, the obturator nerve (though this may be sacrificed with relative impunity), the levator ani muscles and the lumbo-sacral plexus and rectum 
posteriorly. In extending the excision of the parametrium backwards along the utero-sactal ligaments, care must be taken not to damage the terminal branches of the superior haemorrhoida! artery since such an accident jeopardizes the blood supply to the bowel whereby a fistula may result. If anterior exenteration is to be performed, it is sufficient to transplant the ureters into the sigmoid at the most convenient spot. The amount of hyperchloraemic acidosis resulting from this procedure can be easily controlled by simple alkalis taken by the patient when she feels off-colour, nauseated, thirsty, or has an unpleasant taste in the mouth. An intelligent patient will soon know the warning symptoms. Control of the anal sphincter and moderation of fluid intake should give the patient an uninterrupted six to eight hours sleep and enable her to perform most social activities.

Total exenteration presents certain problems which must be solved if this operation is to survive as a reasonable surgical procedure :

$a$. It is universally acknowledged that a wet colostomy is unpleasant and often unmanageable.

$b$. The implantation of the ureters in the large bowel, as already pointed out, is fraught with grave risk to the kidney from infection and obstruction.

$c$. The electrolyte disturbance from the selective absorption of chloride from the bowel urine is upsetting and unpleasant to the patient and may prove a danger. It is, therefore, suggested that a separate artificial bladder made from an isolated loop of terminal ileum, one end of which is closed and the other brought out in the right lower quadrant as a permanent ileostomy, should be imployed. Clean urine can thus be collected, uncontaminated with faeces, in a separate bag while an ordinary colostomy in the left side of the abdomen can be trained to operate regularly once every morning, thus causing the patient little or no disability. The presence of the ureter in an isolated loop of ileum uncontaminated by bowel contents should diminish the risks of infection to the kidney.

There is one further danger of total exenteration to the patient, namely, the raw area left by the extirpation of the pelvic viscera. Infection in this raw area is unavoidable and the adhesion of coils of small bowel to it provide a real danger of intestinal obstruction. It is suggested, therefore, by the author that a two-stage operation should be performed for total pelvic exenteration. In the first stage, the permanent colostomy is formed and the artificial bladder is established with implantation of both ureters into it. Some form of peritoneal shelf should be constructed between these two artificial stomata so that the small bowel is unable to prolapse into the pelvis. After a reasonable interval, the total exenteration can be completed as a more or less extra-peritoneal procedure, if necessary by a transverse sub-umbilical incision. By this method, it is hoped to eliminate the risks of intestinal obstruction. This complication has too often proved a real and, in some cases, lethal danger to those cases in which total exenteration has been performed.

\section{REFERENCES}

I. KO'TTMEIER, H. L. (1955), f. Obstet. and Gyn., Brit. Emp., 62, 741 .

2. DOBBIE, B. M. W. (1955), F. Obstet. and Gyn., Brit. Emp., 62, 765 .

3. SCHLINK, H. H. (1950), F. Obstet. and Gyn., Brit. Emp., 57,714 .

4. CURRIE, D. W. (1952), Proc. Roy. Soc. Med., 45, 327.

5. GLUCKSMANN, A., and WAY, S. (1948), Ұ. Obst. and Gyn., Brit. Emp., 55, 573.

6. HOWKINS, J. (195I), Lancet, April 21, p. 872.

7. CURRIE, D. W., Personal communication.

\section{Continued from page $52 \mathrm{1}-$ Y. A. Stallworthy, M.A., F.R.C.S., F.R.C.O.G., F.A.C.S.(Hon.)}

ultimate aim, however, should be to prevent pelvic infection from occurring by the better control of pulmonary tuberculosis and the immunization of infants exposed to infection.

\section{BIBLIOGRAPHY}

ASPLUND, J., and RYDEN, A. B. V. (1952), Acta. Obstet. Gynec. Scand., 31, 186.

BARNES, T. (1955), f. Obstet. Gynaec. Brit. Emp., 62, 162. EKENGREN, K. (1955), Acta. Radiol. Stockh. Suppl., I 23.

GREENHILL, J. P. (I94I), 'Year Book of Obstetrics and Gynecology,' The Year Book Publishers, Chicago.

GREENHILL, J. P. (1942), Ibid.

HALBRECHT, I. (1947), Lancet ii, 947.

JEDBERG, H. (1950), Acta. Obstet. Gynec. Scand., 31, Suppl. I.

O'BRIEN, J. R., and LAWLOR, M. K. (1947), F. Obstet. Gynaec. Brit. Emp., 54, 639.

MAGNUSSON, W. (1945), Acta. Radiol. Stockh., 26, 264.
MORGAGNI, J. B. (I744). 'De Sedibus et Causis Mortorum Epistola 38, No. 34. E. D. Radius.'

RABAU, E. et al. (1943), F. Amer. Med. Ass., 122, 801 .

RABAU, E. (1952), F. Obstet. Gynaec. Brit. Emp., 59, 743.

SCHOCKAERT, J. A., and FERIN, J. (1939), Bull. Soc. Belg. Gynec. Obstet., 15, 407.

SHARMAN, A. (1947), Brit. med. $\mathcal{F}$., ii, 83.

STALLWORTHY, J. A. (1952), f. Obstet. Gynaec. Brit. Emp., 59, 729.

STALLWORTHY, J. A. (1954), Med. World, Vol. 80, 3, 258.

STALLWORTHY, J. A. (1955), in Bourne, A. (Ed.), British Gynaec. Practice, Heinemann, London, 530.

SUN, K. (1948), Amer. F. Obst. Gyn., 55, 953.

SUTHERLAND, A. M. (1943), F. Obstet. Gynaec. Brit. Emp., 50, I6I.

SUTHERLAND, A. M. (1950), Lanc2t, ii, 742.

SUTHERLAND, A. M. (1954), F. Obstet. Gynaec. Brit. Emp., 61, 614.

WILLIAMS, E. O. (1955), Ibid., 62, 823. 